\title{
Effect of Oral Treatment with Pyrazole Carbohydrazide Derivatives against Murine Infection by Leishmania amazonensis
}

\author{
Karen S. Charret, Raquel F. Rodrigues, Alice M. R. Bernardino, Adriana O. Gomes, Adriana V. Carvalho, \\ Marilene M. Canto-Cavalheiro, Leonor Leon, and Veronica F. Amaral* \\ Laboratório de Bioquímica de Tripanosomatídeos, Instituto Oswaldo Cruz, Fundação Oswaldo Cruz, Rio de Janeiro, Brazil; \\ Instituto de Química, Departamento de Química Orgânica, Universidade Federal Fluminense, Programa de Pós-graduação em \\ Química Orgânica, Niterói, Brazil; Instituto de Biologia, Departamento de Imunobiologia, Universidade Federal Fluminense, \\ Niterói, Brazil
}

Abstract. Newly synthesized pyrazole carbohydrazide derivatives with substituents $\mathrm{X}=\mathrm{Br} / \mathrm{Y}=\mathrm{NO}$, and $\mathrm{X}=$ $\mathrm{NO}_{2} / \mathrm{Y}=\mathrm{Cl}$ were independently investigated in the CBA mouse model of cutaneous leishmaniasis. Animals were infected with Leishmania amazonensis and treated two weeks after the parasitic infection with the pyrazole carbohydrazides for 45 days. Oral treatment with both compounds controlled evolution of footpad cutaneous lesions and dissemination of parasites to draining lymph nodes. Nitric oxide generation was observed in supernatants of lymph node cells from infected CBA mice that were treated with these compounds. The pyrazole carbohydrazide derivatives did not show any toxicity or cause alterations in body weight, plasma concentrations of alanine aminotransferase and aspartate aminotransferase, and urinary creatinine levels, but promoted a small decrease in blood neutrophils. These results provide new perspectives on the development of drugs with activities against leishmaniasis.

\section{INTRODUCTION}

Leishmaniasis is an important parasitic disease that affects approximately two million persons per year, with approximately 350 million persons at risk of infection..$^{1}$ It is caused by protozoans of the genus Leishmania and the bite of phlebotomine sand flies. In Brazil, Leishmania amazonensis is responsible for most cases reported, which include cutaneous, mucosal, diffuse cutaneous, and visceral leishmaniasis, and is considered a species of epidemiologic importance. ${ }^{2-4}$

Since 1960, chemotherapy for leishmaniasis has relied on administration of pentavalent antimonials compounds such as sodium stibogluconate (Pentostam; Glaxo Wellcome; Brentford, United Kingdom) and meglumine antimoniate (Glucantime; Aventis, Paris, France) as first-line agents., However, these compounds show serious toxic effects and resistance to these drugs is increasing. Amphotericin B, pentamidine, and nonparenteral miltefosine are alternative chemotherapy that has been introduced in recent decades. However, these drugs also show complications such as side effects and high costs. ${ }^{78}$ Thus, there is an urgency for development of affordable and less-toxic alternative drugs. Development of a single drug or formulation for the treatment of several clinical forms of leishmaniasis must address the issue that each infection imposes different pharmacokinetic requirements for the drugs to be used. Other aspects, such as variation in sensitivity of different Leishmania species and increased resistance of parasites to drugs, must also be considered. ${ }^{9}$ Successful treatment depends on compounds with activity against Leishmania species and an immunomodulatory effect.

Pyrazole carbohydrazides are compounds with antiinflammatory, analgesic, and anti-thrombotic effects ${ }^{10}$ and anti-viral and anti-tumor activities. ${ }^{11}$ We have previously demonstrated the anti-Leishmania in vitro activity of 1-(4-X-phenyl)$\mathrm{N}^{\prime}$-[(4-Y-phenyl) methylene]-1H-pyrazole-4-carbohydrazide derivatives. $^{12}$

\footnotetext{
* Address correspondence to Veronica F. Amaral, Instituto Biologia, Departamento de Imunobiologia, Universidade Federal Fluminense, Outeiro de São João Baptista, Valonguinho, CEP 24020-150, Niterói, RJ, Brazil.E-mail: vfa@vm.uff.br
}

In the present study, we evaluated pyrazolic carbohydrazide (Figure 1) compounds with $\mathrm{X}=\mathrm{Br} / \mathrm{Y}=\mathrm{NO}_{2}$ (compound 1) and $\mathrm{X}=\mathrm{NO}_{2} / \mathrm{Y}=\mathrm{Cl}$ (compound 2) substituents in experimental infection of CBA mice with Leishmania amazonensis and assessed drug effectiveness by lesion size and parasite burden. We also analyzed toxic effects in infected and noninfected CBA mice by body weight, leukocyte counts, and levels of aminotransferases and creatinine. Nitric oxide production by these compounds was also investigated in draining lymph nodes and spleen cells for an association with disease evolution.

\section{MATERIALS AND METHODS}

Parasites. Leishmania amazonensis (MHOM/BR/77LTB 0016 strain) was maintained by animal passage and cryopreserved in liquid nitrogen. Promastigotes were cultured in Schneider's Drosophila medium, pH 7.2 (Sigma, St. Louis, MO) supplemented with $10 \%(\mathrm{v} / \mathrm{v})$ heat-inactivated fetal calf serum. Characterization of strains was made by using molecular techniques such as isoenzyme electrophoresis. ${ }^{13}$

Animals. Mice (males, eight weeks of age) were acquired from the Nucleus for Laboratory Animals-Universidade Federal Fluminense and the Center for Biological Evaluation and Care of Research Animals-FIOCRUZ. Each experimental group contained eight animals. Experiments were conducted using a protocol (P0020-00) reviewed and approved by the Institutional Committee of CEUA/FIOCRUZ.

Chemicals. The 1-(4-X-phenyl)- $\mathrm{N}^{\prime}-[(4-\mathrm{Y}$-phenyl) methylene]-1H-pyrazole-4-carbohydrazides with substituents $\mathrm{X}=$ $\mathrm{Br} / \mathrm{Y}=\mathrm{NO}_{2}$ and $\mathrm{X}=\mathrm{NO}_{2} / \mathrm{Y}=\mathrm{Cl}$ were synthesized by using a molecular hybridization approach. Structures (Figure 1) of these stable crystalline compounds were characterized by standard methods (infrared spectroscopy, ${ }^{1} \mathrm{H}$ analysis, ${ }^{13} \mathrm{C}$-nuclear magnetic resonance). ${ }^{12}$ Ketoconazole (Galena Química e Farmacêutica Ltda, Campinas, SP, Brazil) was used as a reference drug.

Evaluation of in vivo activity. Mice were inoculated in the left hind footpad with $1 \times 10^{6}$ promastigotes of L. amazonensis. Animals were treated orally with pyrazole carbohydrazide 

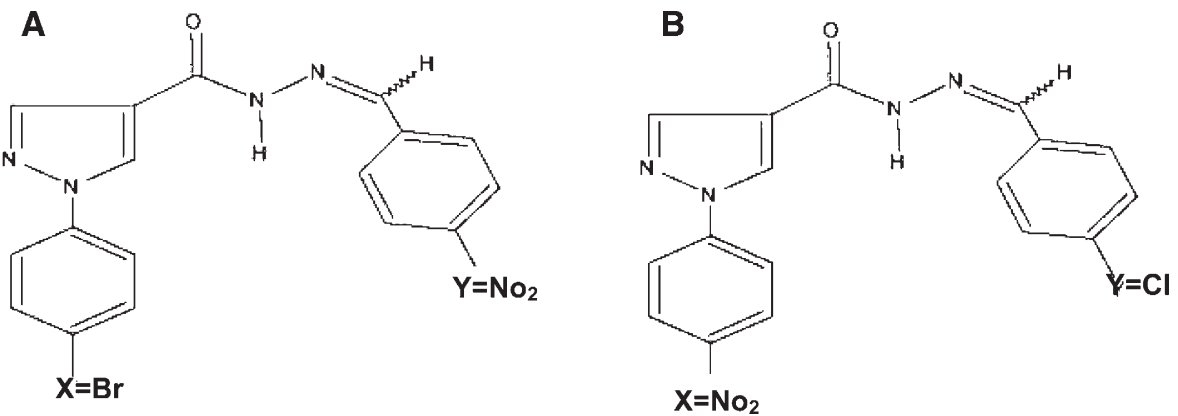

FIgURE 1. Chemical structure of $\mathbf{A}, 1$ and $\mathbf{B}, 2$ pyrazole carbohydrazide derivatives.

compounds $\left(1.7 \mathrm{mg} / \mathrm{kg} /\right.$ day for $\mathrm{Br}-0 \mathrm{NO}_{2}$ and $1.5 \mathrm{mg} / \mathrm{kg} /$ day for $\left.\mathrm{NO}_{2}-\mathrm{Cl}\right)$ and ketoconazole $(50 \mathrm{mg} / \mathrm{kg} /$ day $)$ from the second week after infection continuously up to 45 days after infection. Lesion thickness was evaluated weekly by measuring diameters of both rear feet with a direct-reading dial caliper (Mitutoyo, Yokohama, Japan). Size of lesions in millimeters was calculated by subtracting the measurement of the uninfected foot from that of the infected foot.

Parasite quantification. Number of parasites in lymph nodes was estimated by a modified limiting-dilution assay. ${ }^{14}$ Popliteal lymph nodes of infected footpads were removed and used to prepare a cell suspension in phosphate-buffered saline. After centrifugation of the suspension at 1,500 rpm for 10 minutes, the pellet was resuspended in Schneider's Drosophila medium, pH 7.2. The suspension was then serially diluted in eight-fold dilutions, incubated at $26^{\circ} \mathrm{C}$ for 7 days, and monitored in an inverted microscope for presence or absence of promastigotes. Analyses were by using the L-calc shortcut program (StemSoft Software, Inc., Vancouver, British Columbia, Canada).

Toxicologic study. Body weight, leukocyte counts, and levels of aminotranferases and creatinine were monitored in infected and non-infected and treated and non-treated groups. The treatment schedule for the non-infected groups was the same as that for the infected groups. To assay body weight, mice were weighed during and at the end of the experiment to compare the treated and non-treated mice. To assay aminotransferase levels, blood was drawn from the tail vein during and at the end of treatment. Plasma concentration of alanine aminotransferase (ALT) and aspartate aminotransferase (AST) was detected by using a commercial assay (LabTest; Lagoa Santa, Minais Gerais, Brazil). To assay creatinine levels, urine was collected from mice during and at the end of treatment and tested by using a commercial assay (LabTest). To measure leukocyte counts, total blood leukocytes were counted in a hemocytometer after addition of Turk's solution at a dilution of 1:50, and specific populations of leukocytes were identified by optical microscopy after samples were stained with May-Grunwald reagent.

Nitric oxide dosage. Cells were obtained from spleen or popliteal lymph nodes of infected and non-infected mice and cultured in RPMI 1640 medium (Sigma) without stimulation for 48 hours at $37^{\circ} \mathrm{C}$ in an atmosphere of $5 \% \mathrm{CO}_{2}$. The culture supernatant was analyzed for nitric oxide by using a Griess reaction on a 96-well plate and read at $510 \mathrm{~nm}$ in a spectrophotometer. ${ }^{15}$
Statistical analysis. Data were analyzed by the Student's $t$-test. $P$ values $\leq 0.05$ were considered significant. The InStat program (Graph Pad Software, San Diego, CA) was used for these tests. All experiments were repeated at least three times.

\section{RESULTS}

Therapeutic effects of pyrazole carbohydrazide derivatives on a murine model of infection by $L$. amazonensis. In preliminary studies, leishmanicidal activity and cytotoxicity screening tests were used in vitro assays with pyrazole carbohydrazide derivatives. Compounds $1\left(\mathrm{X}=\mathrm{Br}, \mathrm{Y}=\mathrm{NO}_{2}\right)$ and $2\left(\mathrm{X}=\mathrm{NO}_{2}\right.$, $\mathrm{Y}=\mathrm{Cl}$ ) showed better leishmanicidal activity, as demonstrated by mild toxicity in mammalian cells. This study confirmed the marked leishmanicidal activity of new pyrazole carbohydrazides on L. amazonensis. ${ }^{12}$ Thus, these derivatives were selected for chemotherapeutic experiments in the murine model of leishmaniasis.

The CBA mice were subcutaneously infected with $1 \times$ $10^{6} \mathrm{~L}$. amazonensis promastigotes and orally treated with the compounds 1 and 2 (Figure 1) two weeks after of infection for 45 days continuously. All animals had skin lesions of an erythematous papular nature by the fifth week after infection. Treated animals showed a significant reduction in the size of skin lesions $(P \leq 0.05)$ during the sixth and 23rd weeks post-infection (Figure 2). Results with these new compounds were similar to those with ketoconazole. Although cutaneous lesions in treated animals were smaller than those in untreated animals, the presence of edema and erythema indicated establishment of an inflammatory process with reduced severity of lesions. None of the lesions healed completely.

To better understand the effects of compounds 1 and 2 on the spread of the parasite in the host, we analyzed parasite burden in the spleen and lymph nodes of infected animals. These compounds reduced approximately $98 \%$ of the parasite burden from popliteal lymph nodes. The reference drug ketoconazole eliminated $99 \%$ of the parasites. Thus, at the 16th week post-infection, treatment with pyrazole carbohydrazides showed a significant decrease in parasite burden compared with the untreated control $(P \leq 0.05)$ (Figure 3$)$. At 16th week post-infection, parasites were not isolated from spleens of all groups of animals. Additionally, weights of the lymph node and spleen measured at the 16th week postinfection showed weights comparable to those in non-treated infected mice. 


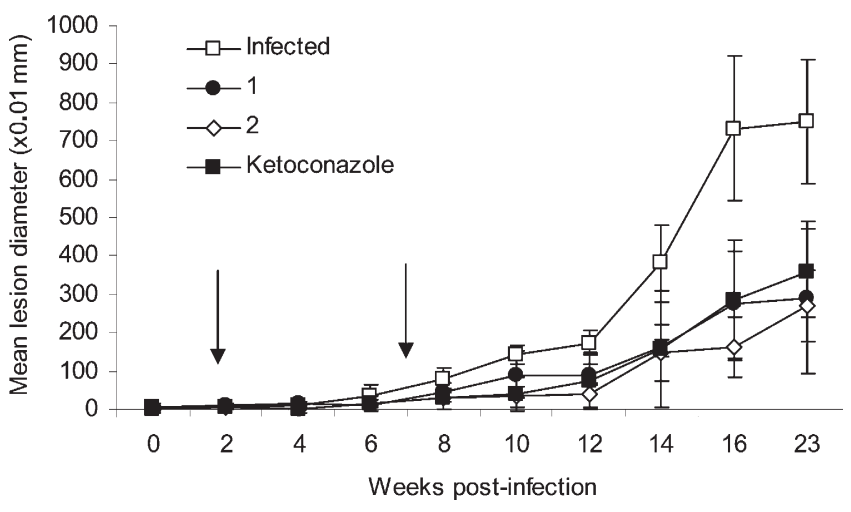

Figure 2. Mean lesion diameter of CBA mice infected with Leishmania amazonensis (MHOM/BR/77LTB0016) and treated with pyrazole carbohydrazide derivatives 1 and 2, ketoconazole as a control, or not treated. Treatment (arrows) started at the second week post-infection and continued up to 45 days post-infection $(n=8$ per group).

Toxicologic effects of pyrazole carbohydrazide derivatives in the murine model. During the treatment period with the two pyrazole carbohydrazide derivatives, we conducted a toxicologic evaluation of healthy animals and those infected with L. amazonensis. Body weight was used as an indicator of systemic toxicity. Compounds 1 or 2 did not show an effect on body weight in infected and uninfected animals (Table 1). Possible alterations of renal and hepatic functions in healthy animals or those infected with L. amazonensis and treated with these compounds were detected by analysis of urine creatinine and hepatic aminotransferase levels. No significant increase in plasma ALT and AST levels was observed in noninfected and infected mice (Table 1) after 42 days of treatment compared with the levels in healthy animals that did not receive treatment. When compared with control animals, non-infected animals and those infected with L. amazonensis did not show any changes in urine creatinine levels 14 and 42 days after treatment (Table 1).

Potential hematologic changes were also used as a measure of toxicity. During the period of infection with L. amazonensis, there was a moderate variation in the leukocyte count of total peripheral blood. Mice treated with the compound 1 showed a slight decrease in total number of leukocytes during the second week of treatment. However, there was no significant change in leukocyte counts in treated animals relative

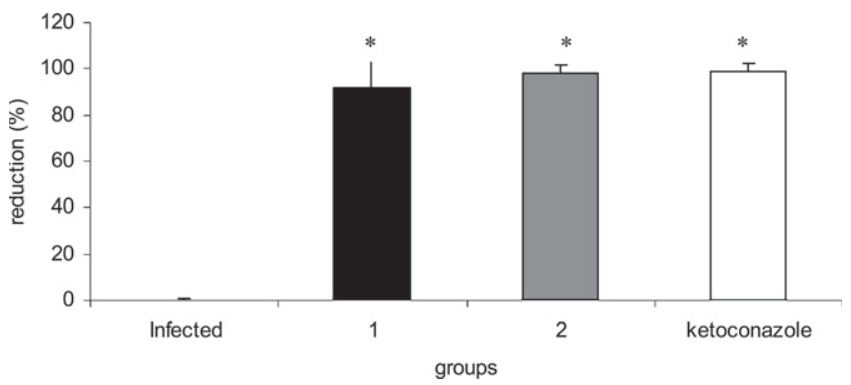

FIGURE 3. Reduction of parasite burden 16 weeks post-infection with Leishmania amazonensis in popliteal lymph nodes of mice orally treated with pyrazole carbohydrazide derivatives up to 45 days postinfection compared with untreated mice ( $\mathrm{n}=8$ per group). Significance levels comparing treatment compounds and infected mice are indicated. $* P \leq 0.05$. to those in untreated animals in the absence of infection. At the end of treatment with both compounds, we observed a decrease in neutrophils in mice infected with L. amazonensis compared with infected animals that were not treated (Figure 4).

Effect of pyrazole carbohydrazide derivatives on production of nitric oxide. Compounds 1 and 2 were further examined for their effects on generation of nitric oxide by spleen and lymph node cells of non-infected mice after 42 days of treatment. Administration of compound 1 clearly increased production of nitric oxide 24 hours after cell culture in lymph node cells, but not in spleen cells. In addition, treatment with compound 2 did affect production of nitric oxide 24 hours after cell culture in lymph node cells or spleen cells. There was no significant difference in production of nitric oxide after 48 hours of lymph node and spleen cell culture of cells from mice treated with both compounds. Treatment with compounds 1 or 2 induced production of nitric oxide 48 hours after cell culture in lymph node cells, but not in spleen cells, from animals at 16 weeks post-infection (Figure 5).

\section{DISCUSSION}

Our data highlight new insights for therapy of murine experimental cutaneous leishmaniasis and make use of oral administration of two independent pyrazole carbohydrazides derivatives. Results verify their capacity to control cutaneous lesion evolution in CBA mice infected with L. amazonensis.

In an earlier report, ${ }^{12}$ we evaluated the in vitro leishmanicidal activity and cytotoxic effect of these compounds. This study showed that these compounds had strong activities against promastigotes of L. amazonensis and lower activities against those of L. braziliensis and L. chagasi. Additionally, the in vitro assay with murine peritoneal macrophage showed a low cytotoxic effect of these compounds. When compared with reference drugs such as pentamidine or ketoconazole, in vitro results showed that these reference drugs were more toxic to cells than pyrazole carbohydrazide derivatives.

In this study, CBA mice infected with L. amazonensis and orally treated with pyrazole carbohydrazide derivatives (Figure 1) controlled development of skin lesions. The CBA mice were chosen because they are susceptible to infection with L. amazonensis and develop cutaneous lesions, but do not show metastasis, as do BALB/c mice. ${ }^{16,17}$ The dose used in this experiment was the same used in a previous anti-inflammatory assay with acylhydrazone compounds. ${ }^{18}$ In our study, treatment with these compounds was started in the second week after L. amazonensis infection and continued for 45 days without interruption. Effects of treatment on progression of skin injury were observed between the sixth and 23rd weeks after infection (Figure 2). The dosing scheme of compounds used in this investigation was lower than that used with ketoconazole. Thus, it may be possible to increase the dose of pyrazole carbohydrazides to induce a better therapeutic effect without risks to the animals because these compounds showed less cytotoxicity ${ }^{12}$ when tested in murine macrophages.

A key goal in pharmaceutical development is a good understanding of in vitro and in vivo performance. In a previous in vitro report, ${ }^{12}$ positions of substituents on compound 1 
TABLE 1

Effect of treatment with pyrazole carbohydrazide derivatives 1 and 2 for 45 days in CBA mice (n $=8$ per group) infected with Leishmania amazonensis*

\begin{tabular}{|c|c|c|c|c|c|}
\hline Mouse group & AST (U/mL) & $\operatorname{ALT}(\mathrm{U} / \mathrm{mL})$ & Creatinine $(\mathrm{mg} / \mathrm{dL})$ & Body weight (g) & Leukocytes, $\times 10^{3} / \mu \mathrm{L}$ \\
\hline \multicolumn{6}{|l|}{ Infected } \\
\hline Control & $145 \pm 26$ & $100 \pm 11$ & $3.2 \pm 0.8$ & $25.2 \pm 2.1$ & $9.3 \pm 2.02$ \\
\hline Compound 1 & $100 \pm 24$ & $145 \pm 42$ & $2.58 \pm 0.55$ & $25.2 \pm 1.5$ & $12.5 \pm 2.3$ \\
\hline Compound 2 & $133 \pm 32$ & $80 \pm 36$ & $2.86 \pm 0.6$ & $25.9 \pm 0.7$ & $10.5 \pm 1.6$ \\
\hline \multicolumn{6}{|l|}{ Non-infected } \\
\hline Control & $105 \pm 30$ & $114 \pm 16$ & $3.4 \pm 0.9$ & $25.58 \pm 2$ & ND \\
\hline Compound 1 & $110.5 \pm 21$ & $82 \pm 10$ & $2.7 \pm 1.4$ & $26.6 \pm 2.8$ & ND \\
\hline Compound 2 & $106.66 \pm 24$ & $78 \pm 46$ & $3.4 \pm 0.5$ & $27 \pm 1.8$ & ND \\
\hline
\end{tabular}

$*$ All values correspond to the 42 nd day of treatment. AST $=$ aspartate aminotransferase; ALT $=$ alanine aminotransferase; $\mathrm{ND}=$ not determined.

(Figure 1) showed that $\mathrm{X}=\mathrm{Br}, \mathrm{Y}=\mathrm{NO}_{2}$ was more leishmanicidal than that observed for molecule $2\left(\mathrm{X}=\mathrm{NO}_{2}, \mathrm{Y}=\mathrm{Cl}\right)$. However, in our in vivo experiment with the new pyrazole carbohydrazides, compounds 1 and 2 showed similar inhibition of the progression of cutaneous lesions in CBA mice infected with L. amazonensis. Thus, in the in vivo system, it appeared that different positions of substituents on molecules 1 or 2 did not interfere with therapeutic effectiveness.

Currently, the recommended drugs for the treatment of leishmaniasis are administrated parenterally, which complicates their use. Solubilization of pyrazole carbohydrazides is a prerequisite for drug absorption and in vivo effectiveness. Oral treatment with pyrazole carbohydrazide derivatives showed apparently good absorption in the gastrointestinal tract because these compounds effected the evolution of lesions. Recently, miltefosine, an orally used drug that has shown parasite resistance and teratogenicity, ${ }^{19}$ has been used for treatment of cutaneous ${ }^{9,20}$ and visceral leishmaniasis. ${ }^{21}$ Moreover, ketoconazole has been used as an alternative oral treatment for cutaneous leishmaniasis, and has shown effectiveness comparable to that of pentavalent antimonials. ${ }^{22,23}$ Ketoconazole treatment outcome could be influenced by Leishmania species. $^{24}$ Azoles can inhibit a key enzyme of sterol synthesis. ${ }^{25}$ However, the mechanism of action of pyrazole carbohydrazide is not known.

Parasite burden was investigated in CBA mice infected and treated with these compounds. In draining lymph nodes, parasite burden showed a consistent decrease in both groups of

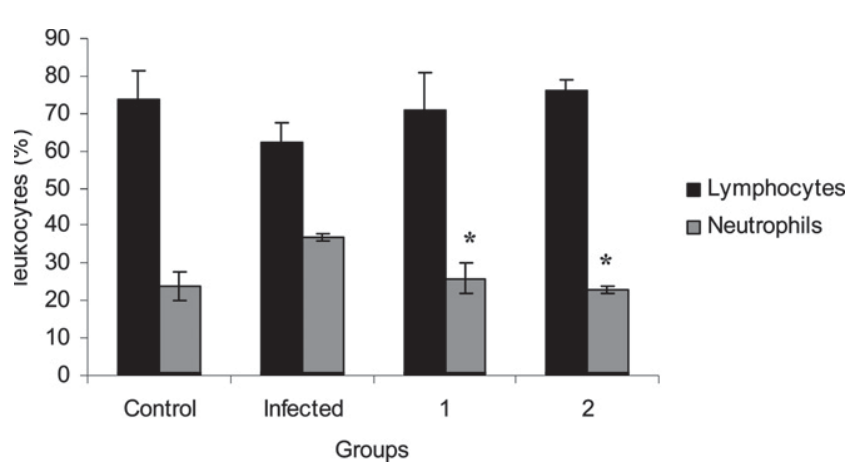

FIGURE 4. Percentage of specific blood leukocyte populations from CBA mice infected with Leishmania amazonensis and treated with pyrazole carbohydrazides for 45 days. All data correspond to the $42 \mathrm{nd}$ day of treatment ( $\mathrm{n}=8$ per group). Cells were counted in by microscopy $(1,000 \times)$ after staining with May-Grünwald reagent. Significance levels comparing treatment compounds and infected mice are indicated. $* P \leq 0.05$. treated mice. Oral administration of compounds 1 and 2 was effective in reducing the number of parasites (98\%). Both compounds were as effective as ketoconazole in reducing parasite burden. In draining lymph nodes (Figure 3), parasite burden was significantly higher in non-treated mice 16 weeks post-infection. Furthermore, BALB/c mice treated with indomethacin, an inhibitor of prostaglandin $\mathrm{E}_{2}$ synthesis, developed smaller cutaneous lesions and lower parasitic burdens compared with the control group. ${ }^{26}$ However, other studies showed that footpad thickness does not always reflect parasite burden and may be influenced by leukocyte infiltration at the infection site..$^{27,28}$ The anti-inflammatory effects on evolution of skin lesions and anti-Leishmania activity of pyrazole carbohydrazide derivatives should be investigated.

CBA mice infected with L. amazonensis had an increase in levels of neutrophils in peripheral blood, which was not observed when animals were infected and treated with pyrazole carbohydrazide derivatives. Levels in treated animals were similar to those in healthy animals. Studies with pyrazole carbohydrazide derivatives have shown several biological activities for these compounds. ${ }^{29,30}$ Some of these pharmacologic properties may be caused by the hydrazone group in this molecule, which determines analgesic, anti-inflammatory, and anti-thrombotic activities. ${ }^{10,31,32}$ Moreover, pyrazole carbohydrazide derivatives also have the pyrazole group and show a variety of pharmacologic properties. In experimental studies, the pyrazoles have shown antimicrobial, ${ }^{33,34}$ antiviral, ${ }^{35}$ and antitumor activities. ${ }^{36,37}$ The pyrazole ring present in some

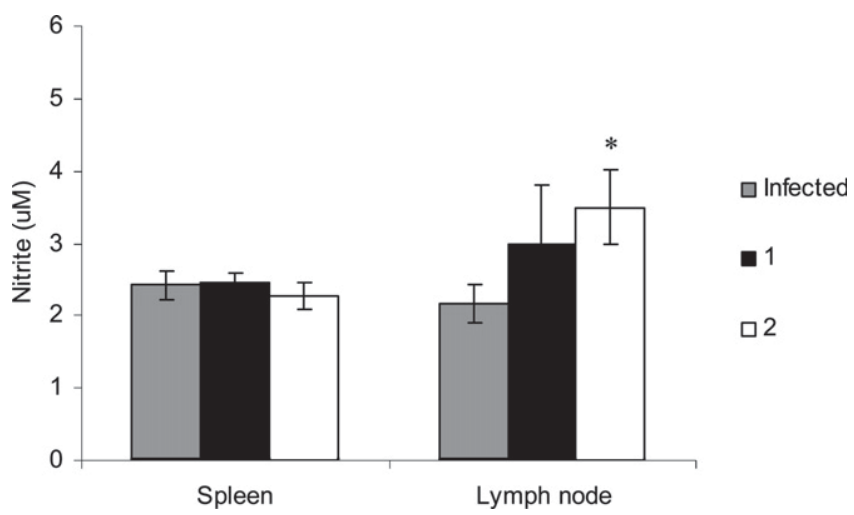

FIGURE 5. Nitric oxide production in mice 16 weeks post-infection with Leishmania amazonensis and treated with pyrazole carbohydrazide derivatives. Nitric oxide was measured in supernatants from unstimulated lymph node cells after culture for 48 hours $(n=8$ per group). Significance levels comparing treatment compounds and infected mice are indicated, $* P \leq 0.05$. 
anti-inflammatory drugs could be responsible for selective inhibition of the cyclooxygenase $2 .^{38}$

The proposed mechanism of action for the biological effects of pyrazole carbohydrazide derivatives may be inhibition of the enzyme 5-lipoxygenase. ${ }^{10,31}$ This enzyme is involved in the arachidonic acid pathway that induces leukotrienes formation. Leukotrienes have several functions, including chemotaxis for neutrophils. ${ }^{39,40}$ Therefore, in this study, the decrease in neutrophils in peripheral blood of treated animals may be caused by inhibition of 5-lipoxygenase.

During evaluation of new synthetic compounds against experimental leishmaniasis in the murine model, it is necessary to evaluate possible toxic effects. These data will enable study and application of the new drugs in the future. The obvious question was to evaluate toxicity in treated animals. This evaluation was performed by assessing body weight, leukocyte counts, hepatic enzymes, and urine creatinine. Systemic toxicity is defined as a reduction in body weight in experimental animals. ${ }^{41}$ In addition to reduction of body weight, systemic toxicity could be manifested through alterations of organ weights. In the present study, there was no alteration in body weights and spleen weights. The effect of the test compounds on leukocyte counts, hepatic enzymes, and urine creatinine was assessed by blood and serum analysis. No alterations in levels of ALT and AST were found. These enzymes have been extensively used as markers for toxicologic study of hepatic functions. ${ }^{42}$

Production of nitric oxide by macrophages is essential for controlling growth of L. major ${ }^{43}$ or L. amazonensis. ${ }^{44}$ In treated animals, production of nitric oxide was induced by compound 1 when measured 24 hours after culture of unstimulated lymph node cells. However, when treated animals were infected with L.amazonensis, compounds 1 and 2 induced production of nitric oxide in the lymph node cell culture when measured after 48 hours (Figure 5). This result may be an important factor in controlling infection. In the present study, cells from CBA mice treated with pyrazole carbohydrazide derivatives and infected with L. amazonensis produced more nitric oxide than did cells from untreated susceptible mice.

Conflicting studies have reported a correlation of the capacity of CBA mice infected with L. amazonensis to induce production of nitric oxide with resistance ${ }^{17}$ or susceptibility ${ }^{45}$ to L. amazonensis. Additionally, when nitric oxide was used as an inhibitor of nitric oxide synthase in L. major-infected mice, a considerable increase in parasite burden and development of larger skin lesions was observed, ${ }^{43,46}$ which corroborated the importance of this mechanism in regulating parasite growth in vivo.

Treatment of CBA mice infected with L. amazonensis with pyrazole carbohydrazide derivatives controlled progression of cutaneous lesions and dissemination of parasite in draining lymph nodes. No toxicity was observed (no variations in AST, ALT, creatinine, or body weight) in treated mice. Thus, the therapeutic effect of these compounds may be comparable with that of ketoconazole. Another feature observed was the capacity to decrease the number of neutrophils in both groups treated with compounds than in infected controls. It has often been suggested that these compounds, in addition to showing leishmanicidal activity reflected in reductions in parasitic burden, may also control evolution of the inflammatory process.
In conclusion, further experiments on dosage optimization and mechanism of action will be carried out. These experiments will involve possible anti-inflammatory effects and antiLeishmania activity to determine an adequate dosing regimen for therapeutic use.

Received July 21, 2008. Accepted for publication September 16, 2008.

Financial support: This work is supported by grants from Conselho Nacional de Desenvolvimento Científico e Tecnológico, Coordenação de Aperfeiçoamento de Pessoal de Nível Superior (CAPES), FIOCRUZ, Universidade Federal Fluminense, Fundação Carlos Chagas Filho de Amparo a Pesquisa do Estado do Rio de Janeiro, Programa de Pós-graduação em Química Orgânica, and fellowships from CAPES, Brazil.

Authors' addresses: Karen S. Charret, Raquel F. Rodrigues, Marilene M. Canto-Cavalheiro, and Leonor Leon, Laboratório de Bioquímica de Tripanosomatídeos, Instituto Oswaldo Cruz, Fundação Oswaldo Cruz, Avenida Brasil, 4.365 pav. 26 sl. 405, Manguinhos, CEP 21045900, Rio de Janeiro, RJ, Brazil. Alice M. R. Bernardino and Adriana O. Gomes, Instituto de Química, Departamento de Química Orgânica, Universidade Federal Fluminense, Programa de Pós-graduação em Química Orgânica, Outeiro de São João Baptista, CEP 24020-150, Niterói, RJ, Brazil. Adriana V. Carvalho and Veronica F. Amaral, Instituto Biologia, Departamento de Imunobiologia, Universidade Federal Fluminense, Outeiro de São João Baptista, Valonguinho, CEP 24020-150, Niterói, RJ, Brazil.

\section{REFERENCES}

1. Desjeux P, 2004. Leishmaniasis: current situation and new perspectives. Comp Immunol Microbiol Infect Dis 27: 305-318.

2. Barral A, Pedral-Sampaio D, Grimaldi Junior G, Momen H, McMahon-Pratt D, Ribeiro de Jesus A, Almeida R, Badaro R, Barral-Netto M, Carvalho EM, Johnson Jr WD, 1991. Leishmaniasis in Bahia, Brazil: evidence that Leishmania amazonensis produces a wide spectrum of clinical disease. Am J Trop Med Hyg 44: 536-546.

3. Leon LL, Barral A, Machado GMC, Grimaldi G Jr, 1992. Antigenic differences among Leishmania amazonensis isolates and their relationships with distinct clinical forms of the disease. Mem Inst Oswaldo Cruz 87: 229-234.

4. Azeredo-Coutinho RB, Conceição-Silva F, Schubach A, Cupolillo E, Quintella LP, Madeira MF, Pacheco RS, Valete-Rosalino CM, Mendonça SC, 2007. First report of diffuse cutaneous leishmaniasis and Leishmania amazonensis infection in Rio de Janeiro State, Brazil. Trans R Soc Trop Med Hyg 101: $735-737$.

5. Herwaldt BL, Berman JD, 1992. Recommendations for treating leishmaniasis with sodium stibogluconate (Pentostam) and review of pertinent clinical studies. Am J Trop Med Hyg 46: 296-306.

6. Croft SL, Coombs GH, 2003. Leishmaniasis current chemotherapy and recent advances in the search for novel drugs. Trends Parasitol 19: 502-508.

7. Sundar S, 2001. Treatment of visceral leishmaniasis. Med Microbiol Immunol (Berl) 190: 89-92.

8. Croft SL, Vivas L, Brooker S, 2003. Recent advances in research and control of malaria, leishmaniasis, trypanosomiasis and schistosomiasis. East Mediterr Health J 9: 518-533.

9. Croft SL, Sundar S, Fairlamb AH, 2006. Drug resistance in and leishmaniasis. Clin Microbiol Rev 19: 111-126.

10. Barreiro EJ, Fraga CA, Miranda Rodrigues AL, 2002. A química medicinal de $\mathrm{N}$-acilidrazonas: novos compostos-protótipos de fármacos analgésicos, antiinflamatórios e anti-trombóticos. Quim Nova 25: 129-148.

11. Rostom SA,Shalaby MA,El-Demellawy MA,2003.Polysubstituted pyrazoles, part 5. Synthesis of new 1-(4-chlorophenyl)-4hydroxy-1H-pyrazole-3-carboxylic acid hydrazide analogs and some derived ring systems. A novel class of potential antitumor and anti-HCV agents. Eur J Med Chem 38: 959-974. 
12. Bernardino AM, Gomes AO, Charret KS, Freitas AC, Machado GM, Canto-Cavalheiro MM, Leon LL, Amaral VF, 2006. Synthesis and leishmanicidal activities of 1-(4-X-phenyl)-N'[(4-Y-phenyl)methylene]-1H-pyrazole-4-carbohydrazides. Eur J Med Chem 41: 80-87.

13. Grimaldi G Jr, David JR, McMahon-Pratt D, 1987. Identification and distribution of New World Leishmania species characterized by serodeme analysis using monoclonal antibodies, 1987 . Am J Trop Med Hyg 36: 270-287. Erratum in Am J Trop Med Hyg 37: 414.

14. Lima HC, Titus RG, 1996. Effects of sand fly vector saliva on development of cutaneous lesions and the immune response to Leishmania braziliensis in $\mathrm{BALB} / \mathrm{c}$ mice. Infect Immun 64: $5442-5445$.

15. Green LC, Wagner DA, Glogowski J, Skipper PL, Wishnok JS, Tannenbaum SR, 1982. Analysis of nitrate, nitrite, and [15N] nitrate in biological fluids. Anal Biochem 126: 131-138.

16. Fournet A, Ferreira ME, Rojas de Arias A, Torres De Ortiz S, Fuentes S, Nakayama H, Schinini A, Hocquemiller R, 1996. In vivo efficacy of oral and intralesional administration of 2-substituted quinolines in experimental treatment of new world cutaneous leishmaniasis caused by Leishmania amazonensis. Antimicrob Agents Chemother 40: 2447-2451.

17. Alves CR, Benévolo de Andrade TC, Alves JL, Pirmez C, 2004. Th1 and Th2 immunological profile induced by cysteine proteinase in murine leishmaniasis. Parasite Immunol 26: $127-135$.

18. Cunha AC, Figueiredo JM, Tributino JL, Miranda AL, Castro HC, Zingali RB, Fraga CA, de Souza MC, Ferreira VF, Barreiro EJ, 2003. Antiplatelet properties of novel N-substituted-phenyl1,2,3-triazole-4-acylhydrazone derivatives. Bioorg Med Chem 11: 2051-2059.

19. Croft SL, Seifert K, Yardley V, 2006. Current scenario of drug development for leishmaniasis. Indian J Med Res 123: 399-410.

20. Soto J, Berman J, 2006. Treatment of New World cutaneous leishmaniasis with miltefosine. Trans $R$ Soc Trop Med Hyg 100: $34-40$.

21. Sundar S, Murray HW, 2005. Availability of miltefosine for the treatment of kala-azar in India. Bull World Health Organ 83: 394-395.

22. Saenz RE, Paz H, Berman JD, 1990. Efficacy of ketoconazole against Leishmania braziliensis panamensis cutaneous leishmaniasis. Am J Med 89: 147-155.

23. Salmanpour R, Handjani F, Nouhpisheh MK, 2001. Comparative study of the efficacy of oral ketoconazole with intra-lesional meglumine antimoniate (Glucantime) for the treatment of cutaneous leishmaniasis. J Dermatolog Treat 12: 159-162.

24. Navin TR, Arana BA, Arana FE, Berman JD, Chajón JF, 1992. Placebo-controlled clinical trial of sodium stibogluconate (Pentostam) versus ketoconazole for treating cutaneous leishmaniasis in Guatemala. J Infect Dis 165: 528-534.

25. Beach DH, Goad LJ, Holz GG Jr, 1988. Effects of antimycotic azoles on growth and sterol biosynthesis of Leishmania promastigotes. Mol Biochem Parasitol 31: 149-162.

26. Guimarães ET, Santos LA, Ribeiro dos Santos R, Teixeira MM, dos Santos WL, Soares MB, 2006. Role of interleukin-4 and prostaglandin E2 in Leishmania amazonensis infection of $\mathrm{BALB} / \mathrm{c}$ mice. Microbes Infect 8: 1219-1226.

27. Oliveira MR, Alves TR, Pinto AC, Pereira Hde S, Leão-Ferreira LR, Moussatché N, de Frugulhetti IC, Ferreira VF, de Souza MC, 2004. Synthesis and antiviral activities of new pyrazolo[4,-c]quinolin-3-ones and their ribonucleoside derivatives. Nucleosides Nucleotides Nucleic Acids 23: 735-748.

28. Tavares D, da Conceição Ribeiro R, Carlos da Silva A, 2006. Inflammatory lesion and parasite load are inversely associated in Leishmania amazonensis infected mice genetically selected according to oral tolerance susceptibility. Microbes Infect 8: 957-964.

29. Cunha AC, Figueiredo JM, Tributino JL, Miranda AL, Castro HC, Zingali RB, Fraga CA, de Souza MC, Ferreira VF, Barreiro EJ, 2003. Antiplatelet properties of novel N-substituted-phenyl1,2,3-triazole-4-acylhydrazone derivatives. Bioorg Med Chem 11: 2051-2059.
30. Lima LM, Frattani FS, dos Santos JL, Castro HC, Fraga CA, Zingali RB, Barreiro EJ, 2008. Synthesis and anti-platelet activity of novel arylsulfonate-acylhydrazone derivatives, designed as antithrombotic candidates. Eur J Med Chem 43: 348-356.

31. Matheus ME, Oliveira LF, Freitas AC, Carvalho AM, Barreiro EJ, 1991. Antinociceptive property of new 4-acyl-arylhydrazone pyrazole compounds. Braz J Med Biol Res 24: 1219-1222.

32. Fraga CA, Barreiro EJ, 2006. Medicinal chemistry of N-acylhydrazones: new lead-compounds of analgesic, antiinflammatory and antithrombotic drugs. Curr Med Chem 13: $167-198$.

33. Kucukguzel SC, Kucukguzel I, Ulgen M, 2000. Metabolic and chemical studies on $\mathrm{N}$-(4-chlorobenzyl)-N'-benzoylhydrazine. Farmaco 55: 624-630.

34. Genin MJ, Biles C, Keiser BJ, Poppe SM, Swaney SM, Tarpley WG, Yagi Y, Romero DL, 2000. Novel 1,5-diphenylpyrazole nonnucleoside HIV-1 reverse transcriptase inhibitors with enhanced activity versus the delavirdine-resistant $\mathrm{P} 236 \mathrm{~L}$ mutant: lead identification and SAR of 3- substituted derivatives. $J$ Med Chem 43: 1034-1040.

35. Storer R, Ashton CJ, Baxter AD, Hann MM, Marr CL, Mason AM, Mo CL, Myers PL, Noble SA, Penn CR, Weir NG, Woods JM, Coe PL, 1999. The synthesis and antiviral activity of 4-fluoro-1beta-D-ribofuranosyl-1H-pyrazole-3-carboxamide. Nucleosides Nucleotides 18: 203-216.

36. Daidone G, Maggio B, Plescia S, Raffa D, Schillaci D, Migliara O, Caruso A, Cutuli VM, Amico-Roxas M, 1998. Synthesis and pharmacological evaluation of 1-methyl-5-[substituted-4 (3H)-oxo-1,2,3-benzotriazin-3-yl]-1 $H$-pyrazole-4-acetic acid derivatives. Farmaco 30: 350-356.

37. Gamage SA, Spicer JA, Rewcastle GW, Milton J, Sohal S, Dangerfield W, Mistry P, Vicker N, Charlton PA, Denny WA, 2002. Structure-activity relationships for pyrido-, imidazo-, pyrazolo-, pyrazino-, and pyrolophenazinecarboxamides as topoisomerase-targeted anticancer agents. $J$ Med Chem 45: 740-743.

38. Palomer A, Cabre F, Pascual J, Campos J, Trujillo MA, Entrena A, Gallo MA, García L, Mauleón D,Espinosa A,2002.Identification of novel cyclooxygenase-2 selective inhibitors using pharmacophore models. J Med Chem 45: 1402-1411.

39. Goetzl EJ, Pickett WC, 1980. The human PMN leukocyte chemotactic activity of complex hydroxy-eicosatetraenoic acids (HETEs). J Immunol 125: 1789-1791.

40. Pettipher ER, Salter ED, Breslow R, Conklyn MJ, Farrell CA, Hingorani GP, Salter ED, Hackman BC, Wimberly DJ, 1993. Specific inhibition of leukotriene B4 (LTB4)-induced neutrophil emigration by 20-hydroxy LTB4: implications for the regulation of inflammatory responses. Br J Pharmacol 110: 423-427.

41. Black DL, Marks TA, 1992. Role of maternal toxicity in assessing developmental toxicity in animals: a discussion. Regul Toxicol Pharmacol 16: 189-202.

42. Bhattacharjee R, Sil PC, 2006. Protein isolate from the herb, Phyllanthus niruri L. (Euphorbiaceae), plays hepatoprotective role against carbon tetrachlorideinduced liver damage via its antioxidant properties. Food Chem Toxicol 45: 817-826.

43. Liew FY, Li Y, Millott S, 1990. Tumor necrosis factor-alpha synergizes with IFN-gamma in mediating killing of Leishmania major through the induction of nitric oxide. J Immunol 145: 4306-4310.

44. Mukbel RM, Patten C Jr, Gibson K, Ghosh M, Petersen C, Jones DE, 2007. Macrophage killing of Leishmania amazonensis amastigotes requires both nitric oxide and superoxide. Am J Trop Med Hyg 76: 669-675.

45. Lemos de Souza V, Ascenção Souza J, Correia Silva TM, Sampaio Tavares Veras P, Rodrigues de-Freitas LA, 2000. Different Leishmania species determine distinct profiles of immune and histopathological responses in CBA mice. Microbes Infect 2: $1807-1815$.

46. Woods ML, Mayer J, Evans TG, Hibbs JB Jr, 1994. Antiparasitic effects of nitric oxide in an in vitro murine model of Chlamydia trachomatis infection and an in vivo murine model of Leishmania major infection. Immunol Ser 60: 179-195. 